\title{
Modelling of reactor pressure vessel subjected to pressurized thermal shock using 3D-XFEM
}

\author{
Diego F. Mora ${ }^{\mathrm{a}, *}$, Markus Niffenegger ${ }^{\mathrm{a}}$, Guian Qian ${ }^{\mathrm{a}, \mathrm{b}}$, Michal Jaros ${ }^{\mathrm{c}}$, Bojan Niceno ${ }^{\mathrm{c}}$ \\ ${ }^{a}$ Paul Scherrer Institut, Nuclear Energy and Safety Department, Structural Integrity Group Forschungsstrasse 111, 5232 Villigen PSI, Switzerland \\ ${ }^{\mathrm{b}}$ State Key Laboratory for Nonlinear Mechanics (LNM), Institute of Mechanics, Chinese Academy of Sciences, Beijing 100190, China \\ ${ }^{c}$ Paul Scherrer Institut, Nuclear Energy and Safety Department, Laboratory for Scientific Computing and Modelling, Forschungsstrasse 111, 5232 Villigen PSI, Switzerland
}

\section{A R T I C L E I N F O}

\section{Keywords:}

Pressurized thermal shock

Large Break LOCA

Stress intensity factor

Reactor pressure vessel

Fracture mechanics

XFEM

\begin{abstract}
A B S T R A C T
We describe the model developed for integrity assessment of a reactor pressure vessel (RPV) subjected to pressurized thermal shock (PTS). The assessment is based on a multi-step simulation scheme, which includes the thermo-hydraulic, thermo-mechanical and fracture mechanics analyses. The thermo-mechanical model uses the three-dimensional finite element method (FEM) to calculate the stress fields of the reactor pressure vessel (RPV) subjected to the thermal load and pressure during large break loss of coolant accident (LBLOCA). In this contribution, the multistep simulation scheme is extended to the analysis of two-phase steam-water flow occurring in the LBLOCA situation and the fracture analysis of postulated cracks under this accident event. It is demonstrated that the principle of the combined one-way coupled system code, CFD and structural mechanics codes can be used for the fracture analysis in case of a transient accident, which involves two-phase flow. The prediction of the temperature field is achieved by using two-phase computational fluid dynamics (CFD) simulation. To perform the stress analysis, an appropriate finite element discretization of the RPV wall is used, which considered the cladding and the ferritic low allow steel. The calculation of the stress intensity factor (SIF) in mode I for hypothetical cracks located in critical positions of the RPV is based on the linear elastic fracture mechanics (LEFM).

The fracture mechanics model is based on the node-based submodeling technique in combination with XFEM in Abaqus. This is used to refine the mesh required by the fracture analysis in the region of interest, especially those regions under the cooling plume formed during the LBLOCA. The submodel may contain three types of cracks: axial, circumferential and inclined. The performed integrity assessment compares the stress intensity factor calculated in the deepest point of a surface crack with the material's fracture toughness. Two approaches to extract the stress intensity factor were applied in the present paper, namely, the classical FEM and eXtended FEM or XFEM. The classical FEM and XFEM solutions are compared. Both techniques give similar results. However, XFEM is more convenient as it is mesh independent.
\end{abstract}

\section{Introduction}

The Reactor Pressure Vessel (RPV) is exposed to an aggressive environment during the operation time (e.g. more than 40 years). During the life time, the neutron irradiation causes embrittlement of RPV ferritic low alloy steels and makes the material susceptible to brittle failure (Odette and Lucas, 1986). Furthermore, with an extension of the NPP operation beyond the scheduled service, ageing degradation mechanisms (e.g. thermo-fatige) could grow initial defects up to a critical size, increasing the susceptibility to failure in the RPV. Therefore, in-depth assessment is required including details uncovered by conventional methods to investigate unfavorable scenarios relevant for the structural integrity. Existing analytical analysis are mostly based on simple crack and structure geometries which do not consider the real conditions of the RPV subjected to a thermal shock due to a Loss of Coolant Accident (LOCA) (Fillery and Hu, 2012; Ma et al., 1994; Oliveira and Wu, 1987). During a LOCA event, the most severe conditions take place when the emergency core cooling (ECC) water is injected inside the cold legs filled initially with hotter water and/or steam. The cooling flow is not homogeneous and it takes a shape of a plume also known as cooling plume (Qian et al., 2016). The rapid cooling of the down-comer and the internal RPV surface followed probably by re-pressurization of the RPV causes large temperature gradients and variation of pressure which induces thermal-mechanical stresses. High tensile circumferential and

\footnotetext{
* Corresponding author.

E-mail address: diego.mora@psi.ch (D.F. Mora).
} 


$\begin{array}{ll}\text { Nomenclature } \\ \text { BC } & \text { boundary condition } \\ \text { CFD } & \text { computational fluid dynamics } \\ \text { CAD } & \text { computer aided design } \\ \text { DC } & \text { downcomer } \\ \text { DFM } & \text { Deterministic Fracture Mechanics } \\ \text { ECCS } & \text { Emergency core cooling system } \\ \text { FEM } & \text { Finite Element Method } \\ \text { LEFM } & \text { Linear Elastic Fracture Mechanics } \\ \text { LBLOCA } & \text { Large Break Loss-Of-Coolant Accident } \\ \text { MBLOCA Medium Break Loss-Of-Coolant Accident } \\ \text { PTS } & \text { Pressurized Thermal Shock } \\ \text { RPV } & \text { Reactor Pressure Vessel } \\ \text { RCS } & \text { Reactor coolant system } \\ \text { SIF } & \text { Stress Intensity Factor } \\ \text { SIP } & \text { Safety injection pumps } \\ \text { SBLOCA } & \text { Small Break Loss-Of-Coolant Accident } \\ \text { XFEM } & \text { eXtended Finite Element Method } \\ a & \text { crack depth [m] } \\ \mathbf{a}_{i}, \mathbf{b}_{i \alpha} & \text { degrees of freedom associated to crack and crack tip, re- } \\ & \text { spectively. } \\ 2 c & \text { crack length [m] } \\ \text { B } & \text { pre-logarithmic energy factor matrix } \\ E & \text { elastic modulus [GPa] } \\ h & \text { height of modeled RPV geometry [m] } \\ I & \text { set of all nodes in the finite element mesh } \\ \text { I } & \text { Second order identity tensor } \\ & \end{array}$

axial stresses in the RPV wall may initiate unstable crack propagation of flaws with or without crack arrest depending on the embrittlement condition of the vessel and $K_{I}$ at the current crack location. More simple conditions of the fluid dynamics such as axisymmetric or uniform fluid (RELAP5-3D, 1999; Williams et al., 2004) are assumed in the prediction of the stress intensity factor in engineering codes such as FAVOR, PASCAL, etc. However, accurate prediction of the SIF should include the fluid dynamics of the two-phase fluid in three dimensions and the thermomechanical behavior of the ferritic steel.

The study of RPV under PTS loading has attracted the attention of the international experts dedicated to the integrity assessment, especially because of the thermal hydraulic aspects. Many international projects were organized to bring together experts to perform detailed analyses of the methods used for this purpose, e.g. (Bass et al., 2001; Lucas et al., 2009). The main outcome of the TH analysis is the thermal and pressure loads affecting the RPV in case of relevant transient. Extreme thermal gradients in the structural components can take place during PTS. Therefore, the fluid temperature must be reliably assessed to predict the loads upon the RPV. One dimensional system codes are widely employed for thermo-hydraulic calculation. In RELAP (RELAP53D, 1999) or TRACE (Murray, 2007) computational codes, transient simulation is reduced to the simplified one-dimensional or axisymmetric case disregarding the real temperature distribution. In case of non-uniform cold down, a more sophisticated way to calculate the complex flow field is needed (Toppila, 2008). Unlike these codes, computational fluid dynamics (CFD) allows us to take into account the detailed geometry and to predict multidimensional features of the PTS in the RPV. Sharabi et al. (Sharabi et al., 2016) presented the CFD results for a hypothetical medium break loss of coolant accident (MBLOCA) in the hot leg and pointed out that CFD models are very time consuming. However, the PTS temperature evolution during the transient is well represented using the three dimensional calculation and the cooling plume is determined in detail.

The thermal hydraulic study can be seen in a multiscale framework, in which the one-dimensional and three dimensional thermal-hydraulic

\begin{tabular}{|c|c|}
\hline$J$ & $J$-Integral $[\mathrm{MPa} \cdot \mathrm{m}]$ \\
\hline$J_{\text {int }}^{\alpha}$ & interaction integral \\
\hline$F_{\alpha}(\boldsymbol{x})$ & crack tip functions \\
\hline$G$ & Shear modulus $[\mathrm{GPa}]$ \\
\hline $\mathcal{G}$ & energy release rate \\
\hline$H(\boldsymbol{x})$ & generalized Heaviside function \\
\hline K & vector of stress intensity factors \\
\hline$K_{\mathrm{I}}$ & mode I linear elastic stress intensity factor $\left[\mathrm{MPa} \cdot \mathrm{m}^{0.5}\right]$ \\
\hline$K_{\text {II }}$ & mode II linear elastic stress intensity factor $\left[\mathrm{MPa} \cdot \mathrm{m}^{0.5}\right]$ \\
\hline$K_{\text {III }}$ & mode III linear elastic stress intensity factor $\left[\mathrm{MPa} \cdot \mathrm{m}^{0.5}\right]$ \\
\hline$K_{\text {IC }}$ & material fracture toughness $\left[\mathrm{MPa} \cdot \mathrm{m}^{0.5}\right]$ \\
\hline $\mathbf{M}$ & Eshelby's momentum tensor \\
\hline$N_{i}(\boldsymbol{x})$ & nodal shape functions \\
\hline$n$ & outward normal to the surface enclosing the crack tip \\
\hline$q_{\mathrm{i}}$ & virtual extension of crack front \\
\hline$q$ & local direction of the virtual crack propagation. \\
\hline$R_{i}$ & inner radius of the modeled RPV geometry [m] \\
\hline$R T_{N D T}$ & Nil-ductility transition reference temperature $\left[{ }^{\circ} \mathrm{C}\right]$ \\
\hline $\mathrm{t}_{\mathrm{c}}$ & thickness of the cladding layer [m] \\
\hline$t_{b}$ & thickness of the base material $[\mathrm{m}]$ \\
\hline$u_{i}, u_{i}^{\text {aux }}$ & displacement and auxiliary displacement components [m] \\
\hline$\alpha$ & auxiliary mode of failure \\
\hline$\delta_{i j}$ & Kronecker delta \\
\hline$\varepsilon, \varepsilon_{\text {aux }}^{\alpha}$ & strain and auxiliary strain tensor \\
\hline$v$ & Poisson's ratio \\
\hline$\sigma, \sigma_{a u x}^{\alpha}$ & stress and auxiliary stress tensor [MPa] \\
\hline$\sigma: \varepsilon$ & Double contraction of second order tensors \\
\hline$\sigma \cdot \mathbf{u}$ & Single contraction of second order tensor and vector \\
\hline
\end{tabular}

studies are preformed sequentially to achieve the temperature distributions (Wang et al., 2017b). The cooling fluid can either be in a single-phase or a two-phase condition, depending on the leak size, its location, and operating conditions of the NPP (Lucas et al., 2009). Lucas et al. (Lucas et al., 2007) showed that the mechanisms involved in the cold-down can individually be simulated. In the two-phase flow scenario, the cold leg is either partially uncovered or completely uncovered. Both situations have to be considered by two-phase flow simulation; in particular, stratified flow with a void fraction ranging from 0 to $100 \%$ needs to be considered for a partially filled cold leg. The simulation of the complex mixing phenomena includes not only stratification in the cold leg but also buoyancy driven plume in the downcomer. Time scale in the transient simulation is also an important aspect. According to Wang (Wang et al., 2017a), in case of SBLOCA transient is sustained for more than ten thousand seconds, while the coolant mixing phenomenon occurs only ten of seconds. Modelling aspects such as convergence and computational mesh are important as they can lead to incorrect flow fields. In general, simulation of PTS is still a big challenge for CFD methods today and the capabilities to simulate the interactions happening in the RPV interior and the overall system performance is not available. Several assumptions have to be made to make the thermo-hydraulic analysis with CFD feasible. The introduction of simplifications as well as the uncertainties in the input parameters and boundary conditions are sources of uncertainties in the results (Boros and Aszódi, 2008; Chauliac et al., 2011). The effect of the uncertainties in the thermo-hydraulic analysis for the vessel failure can be considered by the probabilistic fracture mechanics (PFM) (Qian et al., 2016).

In the present paper, a large break loss of coolant accident (LBLOCA) with a postulated guillotine break in one of the hot legs is analyzed. In the LBLOCA, the loss of coolant causes emptying of the vessel and only the lower plenum contain liquid water at saturation temperature at the beginning of the transient. Since the vessel contains initially vapor and liquid water, the thermo-hydraulic analysis has to consider the two phase flow. In previous studies of SBLOCA and 
MBLOCA, only the liquid water was considered (González-Albuixech et al., 2015; Sharabi et al., 2016). The two-phase steam-water flow in the PWR reactor is studied here using state of the art techniques with ANSYS Fluent code. It is import to remark that the application of CFD to two-phase flow is a proof of the principle of the combined one-way coupled system code, CFD and structural mechanics codes, but need further model development and validation before it can be judged to be sufficiently mature for eventual use in nuclear reactor safety analysis. Pressure drop in LBLOCA is very significant and is faster than in small and medium break cases (SBLOCA and MBLOCA, respectively). This causes a quicker actuation of accumulators resulting in high mass flow rate of emergency core cooling system (ECC) injection from the beginning of the transient. Consequently a large amount of water flows over the hot vessel walls causing significant temperature gradients and, in turn, high thermal loads (Jaros, 2017). The assessment of the stress intensity factor of postulated cracks in the LBLOCA event needs the fracture analysis of the RPV wall under thermomechanical loads. As the complete thermomechanical analysis cannot be executed at once, Gonzalez-Albuixech et al. (González-Albuixech et al., 2016) presented an uncoupled analysis, which consists firstly in solving of the pure thermal problem during LOCA and secondly, the mechanical problem to find the stress field under thermal load and pressure. Finally, the fracture mechanics analysis is performed in the areas of interest, which are dictated by the stress concentration.

The mechanical problem concerns the accurate assessment of the thermomechanical stress distribution in the RPV wall and the fracture analysis of the postulated crack in the internal surface. The numerical structural analysis of the RPV is usually performed within the finite element method (FEM) framework. The stress and subsequent fracture mechanics analysis is carried out with the commercial finite element code (ABAQUS, 2012). To calculate the stress intensity factor (SIF) $\mathrm{K}_{\mathrm{I}}$ of the linear fracture mechanics (LFEM) theory, ABAQUS has two approaches available, namely, the conventional FEM and the extended FEM (XFEM). On one hand, the conventional approach needs the finite element mesh around the crack to be adapted to the geometry imposing serious limitation in complex geometries. On the other hand, this limitation is overcome in XFEM which enriches the finite element approach space with special functions that describes the discontinuity and makes the analysis, up to a certain point, mesh independent (Gravouil et al., 2002; Sukumar et al., 2000). Similarly to CFD calculation, the stress analysis is also time consuming and one alternative is to invoke the submodeling technique to perform the study of local effects such as cracks in a refined model (González-Albuixech et al., 2015).

For characterizing the fracture toughness of the material at different temperatures by using the chemical composition and the neutron fluence, different models, such as the ASME model (ASME, 1995), the Master Curve (ASTM-E1921-02, 1997) and the FAVOR model (Williams et al., 2004), are available. If the stress intensity factor (SIF) is larger than the fracture toughness, crack initiation may occur and, in the worst case even, also fracture. To perform the integrity assessment, $\mathrm{K}_{\mathrm{I}}$ and $\mathrm{K}_{\mathrm{IC}}$ are compared for the whole PTS. A sufficient margin against the brittle failure will assure the structural integrity of the RPV. Today, the analysis of the fracture mechanics in engineering material is often based on the fracture mechanics theory. The linear elastic fracture mechanics (LEFM) was extended to consider other types of materials behaviors such as plastic deformation, viscoelasticity, viscoplasticity, etc. This is referred as nonlinear fracture mechanics. The prediction of the stress intensity factor of the LEFM is expected to be more conservative than the value of the nonlinear fracture mechanics as it does not consider any of the energy dissipation mechanisms. Regarding low steel alloys, exposure to high neutron irradiation can reduce the ability of the material to develop plastic deformation due to the changes in the material at micro and ultrafine scales resulting in embrittlement. This makes the material susceptible to brittle fracture and thus, the use of LEFM for calculating the SIF in this case is a reasonable approach.

Affordable simulation tools for the failure assessment considering the thermo-hydraulic, thermo-mechanical and fracture mechanics analyses at once are not available. Today there exists a collection of simulation software that separately performs these analyses. Thus, reliable results depend on the correctness of the coupling of these packages. This means that technical problems must be overcome to obtain reliable results. A sequence of simulations has to be performed as shown in the flow chart of Fig. 1. The first analysis uses ANSYS Fluent code and consists on the solution of the two-phase flow in order to calculate the temperature distribution, the heat transfer coefficients and pressure in the internal wall surface. The second analysis uses ABAQUS and imposes the thermomechanical loads as boundary conditions to obtain the stress distribution in the RPV wall. Finally, the stress intensity factors are calculated in an ABAQUS sub-model.

\section{Computational fluid dynamics model of PTS}

Large break loss of coolant accident (LBLOCA) with a postulated guillotine break in one of the hot legs is considered to happen in a two loop pressurized water reactor. In this transient, the presence of crack flaws affected by the resulted overcooling of internal surfaces of the RPV may highly contribute to the risk of the vessel to failure, especially if re-pressurization is accompanied. The pressure history during the transient is calculated with RELAP5 and is characterized by significant pressure drop as in Fig. 4. The most significant drop is visible in the very beginning of the transient - before ECC injection starts. In fact, this fast depressurization significantly reduces the impact of pressure on the stresses. In response to this loss of pressure, quick actuation of the accumulators and large mass flow rates of emergency core cooling system (ECCS) injection is observed. As the primary pressure is significantly low, the temperature induces higher stresses than those induced by pressure.

In the considered LOCA scenario, main reactor coolant pumps trip off at start and coast down over $45 \mathrm{~s}$. An emergency shutdown of the nuclear reactor (SCRAM) occurs due to low-pressure signal from the full power. There are two safety injection lines in each loop. Moreover, there are two accumulators considered. Accumulator A injects water at $10{ }^{\circ} \mathrm{C}$ into loop A and accumulator B injects water at the same temperature into loop B. In the analyzed scenario, it is considered that main

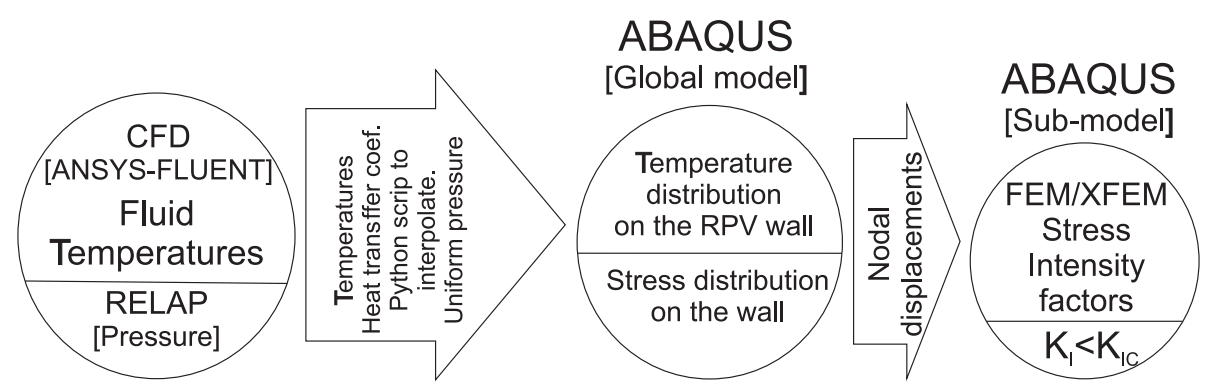

Fig. 1. Uncoupling multistep scheme: thermal-hydraulic simulation with CFD-Fluent, thermo-mechanical ABAQUS-FEM and fracture mechanics analysis with ABAQUS-XFEM for a LBLOCA. 
steam valves remain close, isolating the steam generators (SGs) (Jaros, 2017).

\subsection{Geometry description}

A computer aided design CAD file is constructed for the model RPV representing a reference design of the two-loop PWR. Detailed description of the adopted computational domain is shown in Fig. 2. The three dimensional full description of the RPV with the injection lines connected to the cold legs as well as the ECC injection lines connected to the safety injection pumps (SIP) and accumulator lines are shown.

Different geometrical details of the walls, cold legs, core barrel and neutron shield are represented in the computational model. In particular, exact representation of the inlet nozzle connecting the cold leg and the RPV is taken into account, because the flow has a significant impact on the mechanical behavior in this area. The neutron shield located in the active area of the core, which provides shielding for the complete vessel, represents an obstacle to the flow in the downcomer (Fig. 2). It has a significant influence on the mixing characteristics of the cold water falling down in the downcomer and therefore it is also included in the simulation domain. The hot leg is not considered in the analysis and instead the outlet boundary is placed at the RPV outlet nozzle connecting the hot leg to the RPV. In the simulation, it is assumed that all the flow is eventually directed towards the downcomer. The structural details of the core are not included in the simulation and it is adopted a simplified porous media (Sharabi et al., 2016).

\subsection{Numerical models for CFD}

The two-phase CFD is far from being a closed research topic or sufficiently validated method. Indeed, it is far away from applying twophase CFD for industrially relevant topics as RPV integrity assessment with confidence as it was concluded in Apanasevich et al. (Apanasevich et al., 2014). In this work, the focus is to study the two-phase steamwater flow in the PWR reactor using state of the art techniques (ANSYS Fluent code (ANSYS, 2013)) to evaluate the stresses with 3D-XFEM in case of a LBLOCA. Deficiencies in the validation based on CFD modelling for two-phase PTS have been overviewed in (Lucas et al., 2009; Lucas et al., 2007; Toppila, 2008). CFD calculation implies a given number of approximations and simplifications, which are explained in the present section. Nevertheless, the CFD simulation with ANSYS fluent predicts detailed three-dimensional flow pattern in the cold leg and downcomer that cannot be predicted properly with one-dimensional codes. Thus, the application of CFD code has the ability to represent three-dimensional features of the flow that affects directly the structural response (Sharabi et al., 2016), and is by no means to claim that CFD is mature yet for accurate two-phase flow analysis.

\subsubsection{Multiphase model and phase change mechanisms}

After ECC, the cold water starts to interact with hot steam in the cold legs and turbulent mixing together with phase change mechanisms occur. To consider both the turbulence and the two-phase change mechanism, an unsteady-Reynolds averaged Navier-Stokes (RANS)-CFD simulation was proposed with the ANSYS Fluent code, which has already been used in pressurized thermal shock analyses (Sharabi et al., 2016). Unlike other CFD codes such NEPTUNE_CFD (Coste, 2013) that uses the Large Interface Model for two-phase PTS, when separation between phases is sharp, in ANSYS Fluent the only alternative available is the Volume-of-Fluid (VOF) option. In VOF multiphase model the Lee Model is used by default to capture all relevant phenomena (Lee, 1980). Evaporation and condensation are modeled in the CFD simulation. Phase change mechanisms are considered by using the vapor transport equation with special coefficients, calculated depending on the temperature by the code. Evaporation frequency and condensation frequency are modified and equal to one in order to resemble the real conditions. The values are directly connected with the relaxation time of the bubble formation implemented in the Lee Model (ANSYS, 2013).

\subsubsection{Geometry of the computational domain}

The computer aided design (CAD) three-dimensional model with an exact representation of the two-loop RPV is used as a computational domain for the purpose of the PTS analysis during the LBLOCA scenario (see Fig. 2). It represents a real RPV in which four injection lines are connected to the cold legs. The positions of all SIPs and accumulator entries to the RPV are given in Fig. 2. Each loop consists of two safety injection lines. A thin line connects primary SIPs A and B with both loops. A thick line connects accumulators and the additional SIP D. Phenomena occurring in the cold legs influence the behavior in the downcomer. The curved part of the cold leg has an impact on the flow separation, which contributes to the induced stresses. Thus, high emphasis has been put on the exact representation of the cold legs and the inlet nozzles in the model. Their computational domain ends at a distance of two pipe diameters from the jets. As water is injected into the cold legs, the hot legs is considered not to be particularly relevant for

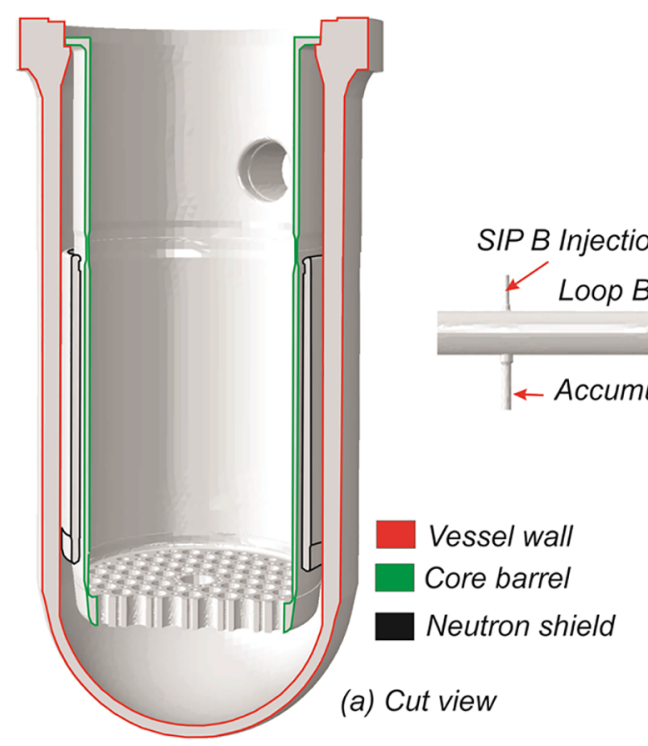

Fig. 2. Guillotine break in one of the hot legs. (a) Cut-view, interior detail and (b) top view geometry of the computational domain. The hot leg and the cold legs are indicated. In each cold leg, the safety injection pumps A, B and D are located as well as the accumulators A and B. 
the PTS investigation. Thus, they are not fully modelled and their computational domain ends at the RPV outlet nozzle.

Another important part of the RPV is the neutron shield, which is a cylindrical wall surrounding the vessel (Fig. 2). It is located between the core barrel and the internal RPV wall. The shield has a non-negligible impact on the flow along the downcomer. The injected cold water hits the shield and splits into two parts. One of them flows attached to the core barrel wall, whereas the other flows down hitting the walls of the RPV. It has an impact on mixing phenomena and thermal stresses in the RPV.

The entire domain of the RPV is divided into two domains, which are depicted in Fig. 3, namely, the fluid and the solid regions. To simulate the two-phase flow, the computational fluid domain is divided into two sub-domains corresponding to water and steam. The density and thermal conductivity are assigned to each domain by using polynomial profiles. The specific heat, viscosity and parameters for mixture are considered to be constant. During the analysis, the vapor volume fraction is calculated with the volume of fluid approach (VOF) using the sharp interface formulation, which models immiscible fluids by solving momentum equations and tracking the volume fractions of the fluids in the whole domain (ANSYS, 2013).

The computational fluid dynamics solver in ANSYS is based on the finite volume method (FVM). The computational fluid domain is divided into a large number of control volumes having the variable of interest located at the centroid of the control volume. In order to obtain flow field aligned with the mesh and to reduce numerical diffusion during calculations, a computational grid of hexahedral cells is used (Mahaffy et al., 2007). Appropriate mesh refinements in zones of crucial importance for the PTS analysis are applied, namely: downcomer, lower plenum, core barrel and cold legs at the nozzles. The total number of elements in the grid is 5.1 million and the total number of nodes is 5.34 million. The grid in all fluid regions consists of approximately 4.4 million elements.

\subsubsection{Turbulence model}

In this approach, the ensemble-averaged momentum equations have a similar form to Navier-Stokes equations. However, velocities and other variables represent the above-mentioned approach ensembleaveraged values. The additional terms called Reynolds Stresses appear due to the time-averaging applied to Navier-Stokes equations, which is predicted using the k- $\varepsilon$ (or k-epsilon) model. Reynolds averaged NavierStokes $\mathrm{k}-\varepsilon$ turbulence approach is also set as default in multiphase calculations in ANSYS Fluent ${ }^{\circledR}$ (ANSYS, 2013). Solid walls of the RPV, neutron shield and core barrel are included using conjugate heat transfer. It is assumed that far from the walls, turbulence is almost isotropic and k- $\varepsilon$ model can work as good as other models. Besides, the most energetic phenomena are interplay of highly energetic inertiadriven plumes at different densities in the core of the reactor. They are more energetic than the turbulence and it is conceivable that turbulence plays a minor role. Besides, near-wall regions are resolved with wallfunction, thus the detailed information of the anisotropy of near-wall turbulence would not be resolve anyway (Jaros, 2017).

\subsection{Initial and boundary conditions}

The selection of the appropriate set of boundary conditions depends on the physical model used (ANSYS Customer Training Material). In order to simulate safety injections from pumps and accumulators, data from RELAP5 calculations are used. To implement these boundary conditions in the corresponding planes, User Defined Functions (UDFs) are used. There are many walls that form the interface between two regions (fluid/solid interface e.g. core barrel wall). Thermal Coupled Condition in these cases is used. It means that no additional thermal boundary conditions are necessary because the solver calculates heat transfer directly from the solution in the adjacent cells. When the wall is not an interface between solid and fluid domain, Heat Flux Thermal
Condition is used with Heat Flux equal to 0 . Such maneuver is used by default and represents an adiabatic wall (ANSYS Fluent Manual). Even though, no backflow is expected in the converged solution, realistic values are set in order to prevent from convergence difficulties in the event that backflows occur (ANSYS Fluent Manual). Other initial conditions used in the CFD simulation are presented below:

- RPV is filled up with steam at saturation temperature

- The lower plenum is filled up with water at saturation temperature

- Pressure is assumed to be uniform in the whole domain and with values in Fig. 4.

The first and second condition above mean that the vessel only contains initially water in the lower plenum at saturation temperature. During LBLOCA, a significant pressure drop is observed in the very beginning of the transient before ECC injection starts (Fig. 4). In the current study, the RELAP5 results for a break size of $3832 \mathrm{~cm}^{2}$ were considered. Safety injection pumps A and B inject water into both loops at $30{ }^{\circ} \mathrm{C}$ when the reactor coolant system (RCS) pressure drops below $10 \mathrm{MPa}$. There is also an additional safety injection pump (SIP) D that injects water at $30^{\circ} \mathrm{C}$ into both loops when RCS pressure drops below 8.4 MPa (Fig. 4). The results from RELAP5 for the mass flow rate from ECC injection presented in Fig. 5 are assumed as boundary conditions for CFD calculation. The thin jet represents the safety injection from SIPs A and B and thick jet represents the safety injection from accumulators A and B and SIP D (Fig. 5-(b)). Note that the injection of the thick jet is one order of magnitude higher than the thin jet. It is assumed that both the SIP and the accumulators inject the emergency water at the same time in order to start the CFD calculations. The starting point for the simulation is set to eight seconds after the beginning of the transient, which represents the starting time of ECC injection (see Fig. 5-(a)). The total amount of water injected through ECCS during the $56 \mathrm{~s}$ of the transient is approximately equal to 14 tons from each loop. It is assumed that the RPV is filled up with steam and the lower plenum is filled up with water, both at saturation temperature. The pressure is uniform in the whole domain, which in the case of double guillotine large break LOCA is considered as a reasonable approximation.

The most relevant initial and boundary conditions are summarized in Table 1 (Jaros, 2017). The injection temperature is assumed constant as a conservative assumption and with the values of the Table 1 .

Fig. 6(a) shows a sequence of snapshots at the beginning of emergency core cooling injection in the cold legs, using as reference value the vapor - value equals to one for vapor volume fraction. Two different mass flow rates interfere with each other in the vicinity of the jets and the volume fraction changes rapidly from the beginning of ECCS actuation $(\mathrm{t}=8.8 \mathrm{~s})$. The injected water interacts with vapor in the cold legs and mixing phenomena occur during the interval $(t=9.2-9.6 \mathrm{~s})$. Contours represent iso-surfaces and show the movement of the injected

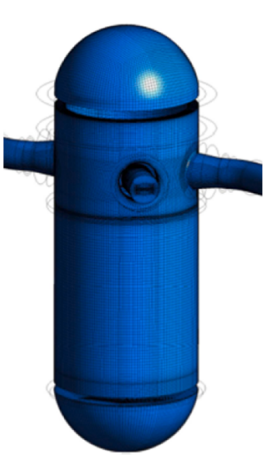

(a)

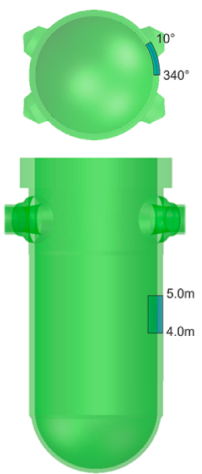

(b)
Fig. 3. (a) Fluid domain and (b) Solid domain. 


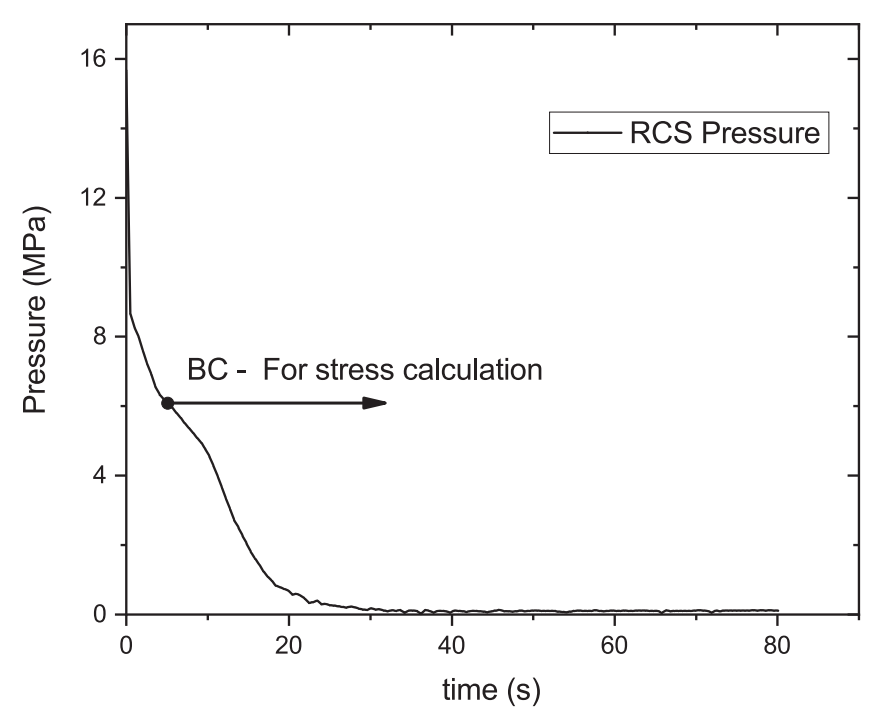

Fig. 4. Inner wall pressure evolution during LBLOCA calculated from RELAP. It is indicated the boundary condition BC for the stress analysis.

water towards the downcomer.

Two different behaviors in the downcomer can be distinguished depending on the mass flow rate of the injected water (Fig. 6(b)). In the beginning, when the mass flow rate is small ( $\mathrm{t}<10.8 \mathrm{~s}$ ), the flow is attached to the internal RPV wall. Later $(t=11.2 \mathrm{~s})$, when the mass flow rate increases, the water partially detaches from the inner RPV wall but subsequently, complete detachment is observed. During $(t=12-12.8 \mathrm{~s})$, more significant amount of water reaches the core barrel wall and the cooling effect on the internal RPV wall is mitigated during this time. The influence of ECC injection along the downcomer is additionally affected by the neutron shield, which is responsible for splitting the cold water stream into two parts $(t=12.8 \mathrm{~s})$, causing additional mixing at the bottom of the downcomer where both water streams interfere before entering the lower plenum.

The mass flow rate of ECC injection evolution in the fluid domain is plotted as 2-D cut-views as in Fig. 6(c), which shows the vapor volume fraction in the RPV. At the beginning of ECC injection $(t=1 \mathrm{~s})$, the reactor is filled up with steam and the lower plenum with water, both at saturation temperature. During LOCA, there is a significant loss of cooling capacity due to the phase change. At low pressure, water evaporates rapidly and the vessel fills up with vapor. At $t=12 \mathrm{~s}$, the injected water starts to flow downwards in the cold legs and along the downcomer. At $21 \mathrm{~s}$, the flow along the downcomer is dominated by

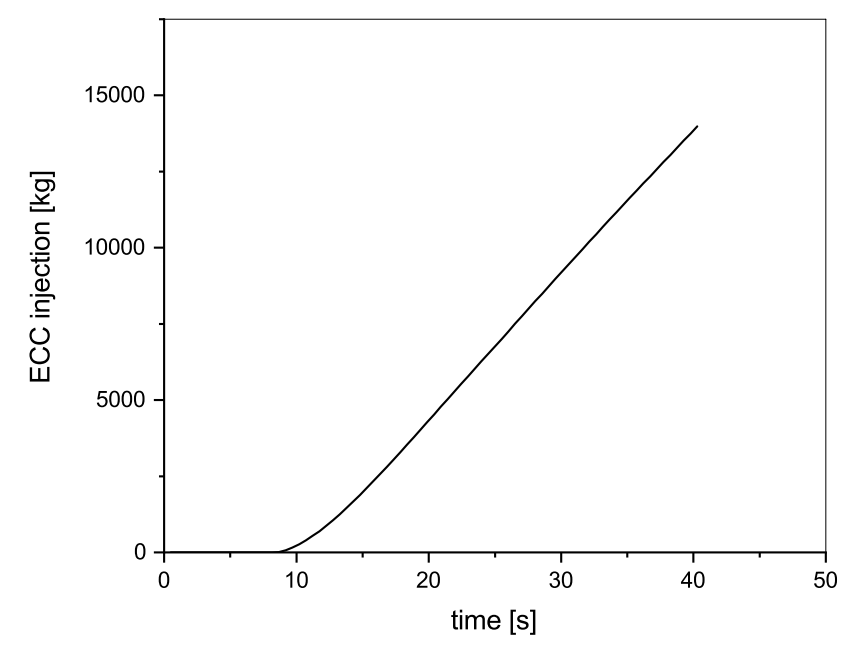

Table 1

Initial and boundary conditions for the CFD model.

\begin{tabular}{ll} 
Initial pressure $[\mathrm{MPa}]$ & 6.9 \\
Initial temperature $\left[{ }^{\circ} \mathrm{C}\right]$ & 285 \\
SIP temperature $\left[{ }^{\circ} \mathrm{C}\right]$ & 30 \\
Accumulator temperature $\left[{ }^{\circ} \mathrm{C}\right]$ & 10 \\
Vapor volume fraction $[-]$ & 1 (except for the lower plenum-0) \\
Velocity throughout the whole domain $[\mathrm{m} / \mathrm{s}]$ & 0 \\
Cold legs, inlet BC & Zero velocity, no heat flux \\
Hot legs, outlet BC & Pressure outlet \\
Wall, BC & Zero velocity, no heat flux \\
\hline
\end{tabular}

water. At this moment, the lower plenum is essentially filled up with water. At $40 \mathrm{~s}$, no changes in the volume fraction are visible in the downcomer as well as the core region.

Temperature in the whole computational domain varies from $283.15 \mathrm{~K}\left(10^{\circ} \mathrm{C}\right)$ up to $558.15 \mathrm{~K}\left(285^{\circ} \mathrm{C}\right)$. The former represents temperature of the water injected by accumulators, whereas the latter is the saturation temperature at $6.9 \mathrm{MPa}$ - initial conditions. Fig. 6(d) shows the development of the temperature in the inner surface of the RPV. At the beginning of ECC injection, the amount of water in the RPV is small and the injected cold water flows attached to the internal RPV wall $(t=10.5 \mathrm{~s})$. As a result, only small thermal gradients in the upper part of the downcomer are visible. After few seconds, the increased mass flow rate causes detachment from the vessel wall $(t=12 \mathrm{~s})$, which is intensified by the presence of the neutron shield and gives rise to the flow separation along the downcomer. Around $t>12 \mathrm{~s}$, the amount of water from ECC injection increases and formation of the cooling plume begins in the vessel wall. The developed thermal gradients is more significant with the increasing ECC injection mass flow rate and after $21 \mathrm{~s}$ of the transient, when the maximum value is reached, the cooling plume in the internal RPV wall is fully developed. The size of the cooling plume reduces after $40 \mathrm{~s}$ and the temperature remains rather uniform.

\section{RPV structural model for the stress analysis}

The stresses in the ferritic low allow steel walls are calculated assuming that the internal surface of the RPV is subjected to a thermal shock. Therefore, the resulting time dependent temperatures, heat transfer coefficient and pressure of the CFD simulation are imposed as boundary conditions in the inner RPV wall surface. The finite element simulation is carried out with a three dimensional model discretized with elements of type DC3D8. The coolant bulk temperature and the heat transfer coefficient are given as input for the mechanical analysis.

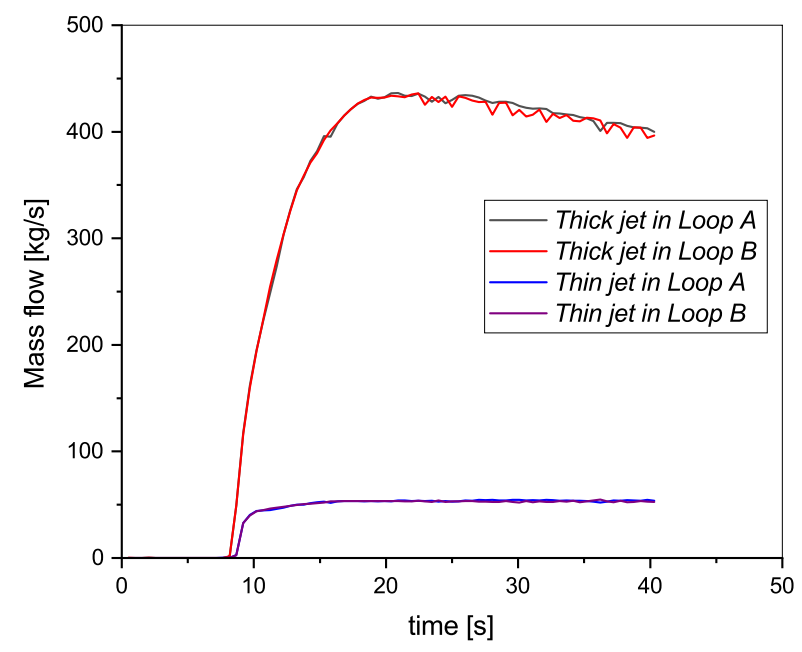

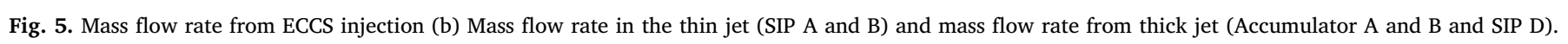



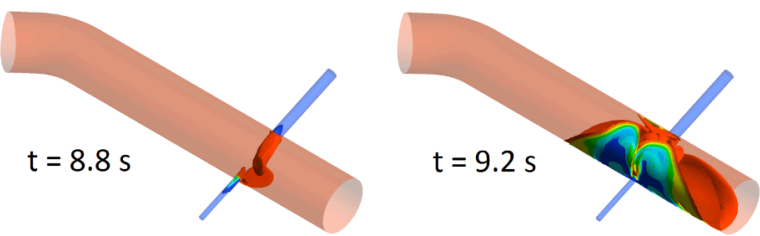

(a)
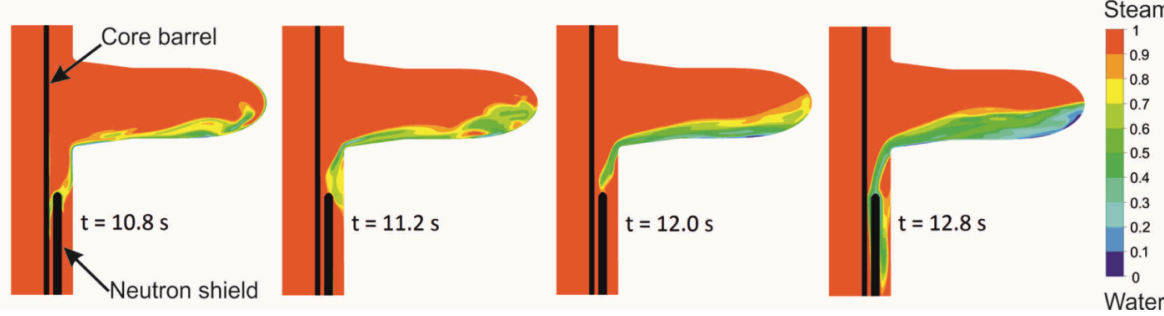

(b)
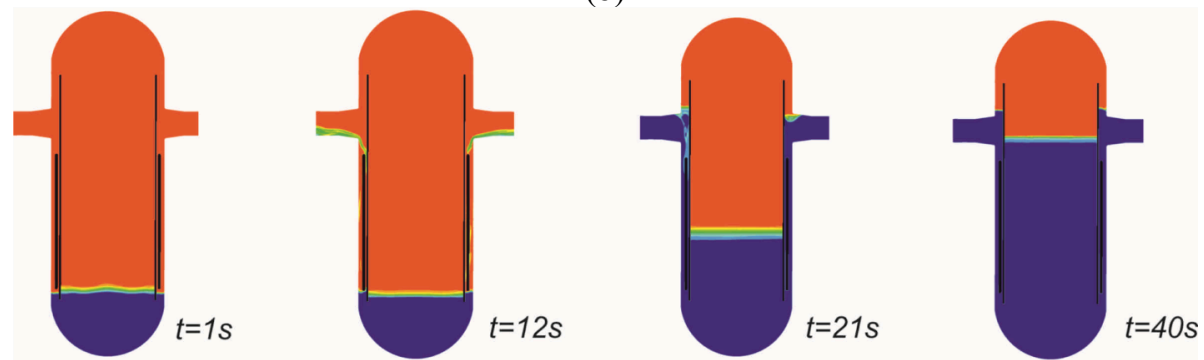

(c)

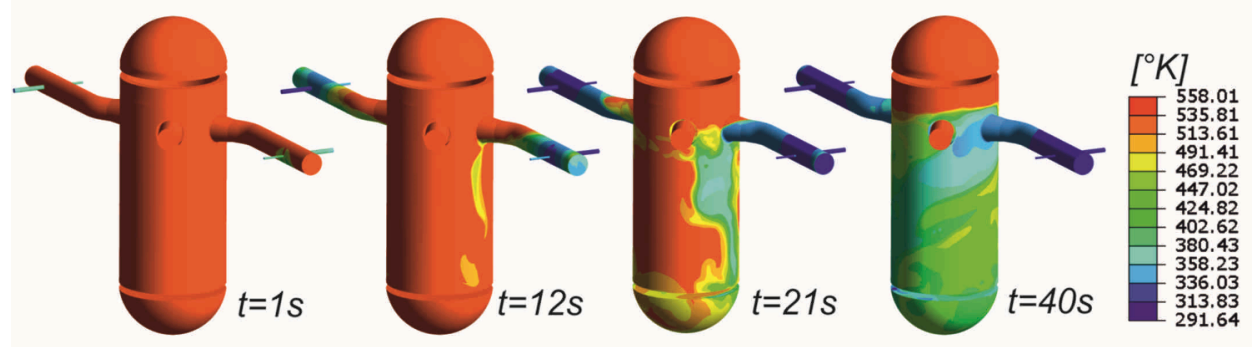

(d)

Fig. 6. Vapor volume fraction in the beginning of ECC injection (loop A), (b) Vapor volume fraction in the downcomer (cross-sectional view - loop A), (c) Vapor volume evolution in the RPV, (d) Development of the thermal plume on the inner surface of RPV.

However, as meshes used in the CFD model and FEM model do not match, interpolation of the temperatures is performed using a Python script. Average size of the elements was $84 \mathrm{~mm}$ and mesh refinement is done in the cladding layer. The mesh is chosen as regular and structured as possible in order to increase the precision of the solution. The material is considered homogenous, isotropic, and elastic and the properties are temperature dependent. The vessel wall is assumed to be at a uniform initial temperature of $285^{\circ} \mathrm{C}$ and thermal boundary conditions were set as adiabatic at the outer surface of the RPV. The coefficient of linear thermal expansion is used according to reference temperature $20^{\circ} \mathrm{C}$. The thermomechanical properties of the material are summarized in Table 2 . The density and the poisson's ratio do not depend on the temperature and have values $7.6 \times 10^{3} \mathrm{~kg} / \mathrm{m}^{3}$ and 0.3 , respectively.

The heat transferred to the ferritic steel due to the thermal shock is calculated with Abaqus following the fourier's law of heat conduction. The solution of the heat transfer problem is the temperature

Table 2

Thermo-mechanical properties of the base material and cladding of the RPV.

\begin{tabular}{|c|c|c|c|c|c|c|c|c|c|c|c|c|}
\hline \multirow[b]{2}{*}{ Temperature $\left[{ }^{\circ} \mathrm{C}\right]$} & \multicolumn{6}{|c|}{ Base material } & \multicolumn{6}{|c|}{ Cladding } \\
\hline & 0.0 & 20 & 100 & 200 & 300 & 400 & 0 & 20 & 100 & 200 & 300 & 400 \\
\hline Elastic Modulus $[\mathrm{GPa}]$ & 206 & 206 & 199 & 190 & 181 & 172 & 200 & 200 & 194 & 186 & 179 & 172 \\
\hline Mean linear thermal expansion coefficient $\left[10^{-6} \mathrm{C}^{-1}\right]$ & 10.3 & 10.3 & 11.1 & 12.1 & 12.9 & 13.5 & 16 & 16 & 16 & 17 & 17 & 18 \\
\hline Thermal conductivity $[\mathrm{W} /(\mathrm{m} \mathrm{K})]$ & 44.4 & 44.4 & 44.4 & 43.2 & 41.8 & 39.4 & 15 & 15 & 16 & 17 & 19 & 21 \\
\hline Specific heat capacity $[\mathrm{J} /(\mathrm{Kg} \mathrm{K})]$ & 450 & 450 & 490 & 520 & 560 & 610 & 500 & 500 & 500 & 540 & 540 & 590 \\
\hline Yield stress of the unirradiated material $[\mathrm{MPa}]$ & & 449.3 & & & & & & 215 & & & & \\
\hline Stress free temperature $\left[{ }^{\circ} \mathrm{C}\right]$ & 280.3 & & & & & & & & & & & \\
\hline
\end{tabular}


distribution in the RPV wall, which is then imposed as a predefined field in the stress analysis. The thermal conductivity and capacity are given in Table 2.

In the second step of the uncoupled scheme a strain-stress calculation based on the temperature field and pressure is carried out. The elastic strain induced by the action of pressure, $\varepsilon_{\sigma}$, and thermal expansion, $\varepsilon_{T}$, gives the total strain $\varepsilon=\varepsilon_{\sigma}+\varepsilon_{T}$, where $\varepsilon_{T}=\alpha \Delta T$ with $\alpha$ being the expansion coefficient. The pressure is described in Fig. 4 and is assumed to be uniformly distributed while the temperature is the result of the heat transfer problem. In order to calculate the stresses, the elements of the finite element mesh are changed to 20-node quadratic bricks with reduced integration (C3D20R).

The evolution of the equivalent von Mises stress in the inner RPV surface is depicted in Fig. 7(a) with stresses ranging [450-700 MPa]. In the present analysis, any type of energy dissipation mechanism in the material behavior such as plasticity, visco-plasticity, etc was not considered. In consequence, the stresses calculated in Abaqus can take values above the strength of the material and the fracture mechanics calculation can overestimate the value of the stress intensity factor. Therefore, the assumption of the linear elastic behavior might lead to conservative values of the SIF. At $11 \mathrm{~s}$, the temperature is no longer uniform in the downcomer and the stress shows non uniform distribution as well. At this moment, water reaches the downcomer and forms the cooling plume. The effect of the cooling plume gives rise to concentration of stresses in the core region. However, the detachment of the fluid due to high flow rate prevents sudden increase of the stress magnitude $(t=12.53 \mathrm{~s})$. During the interval $13 \mathrm{~s}-32 \mathrm{~s}$, water is in contact with the inner RPV surface and generates high stresses in the downcomer. However, the area of high stresses moves as the plume changes its position generating a meandering movement. In the subsequent seconds ( $\mathrm{t}>32 \mathrm{~s}$ ), areas of high stresses due to cooling plume moves to the upper part of the core as the water fills up the vessel. At $40 \mathrm{~s}$, the size of the plume reduces and the stress field becomes more uniform in the core region. In the last seconds ( $t>56 \mathrm{~s}$ ), the plume almost disappears but the vessel remains subjected to a high stress.

Fig. 7(b) presents the hoop and axial stresses for two different times of the transient. In every case, the highest stress values are in the area affected by cooling plume in both directions.

The analysis of the stress distribution allows us to define the location in which the highest stress values of the core beltline region are expected. The circumferential and axial stress evolution in time is shown in Fig. 8(a) in the location SM2 (red point) which is a point in the inner RPV surface. The internal surface wall temperature evolution presents strong oscillations after the beginning of the transient, which is due to the meandering motion of the plume during the filling up of the vessel. After the first $30 \mathrm{~s}$ approximately, the vessel is partially filled and the strong oscillations of the plume cease. After $40 \mathrm{~s}$ the vessel is almost full of water as shown in Fig. 6(c) and temperature curve decreases and reaches a rather stationary value. However, results from CFD calculation are only available up to a certain time (56s), the temperature is linearly extrapolated until $3000 \mathrm{~s}$ using as final temperature the one calculated in RELAP5 at the end of the transient (Fig. 8(b)). This kind of extrapolation was chosen due to the lack of information and may not represent the most conservative assumption. Fig. 8(a) and (b) also show the evolution of the axial and circumferential stresses in the point of interest.
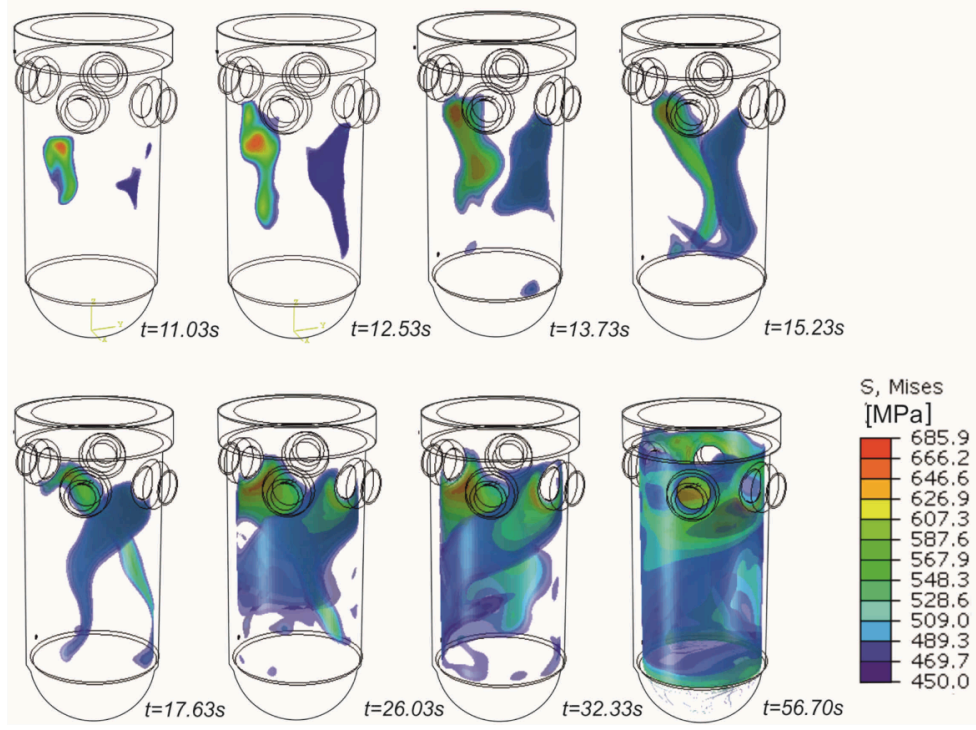

(a)

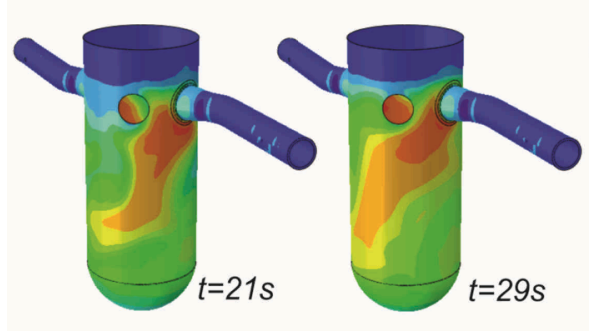

Hoop stress

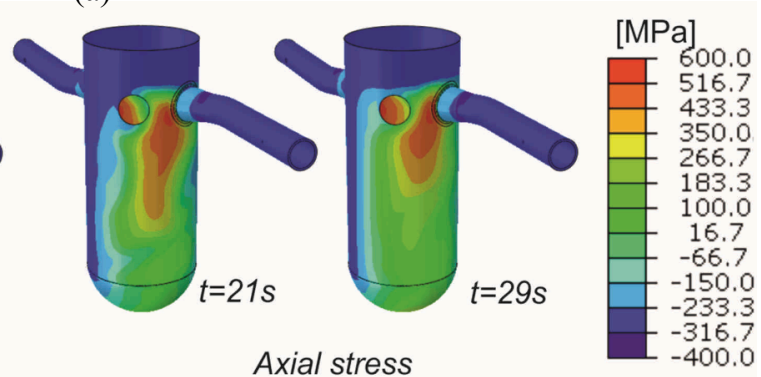

(b)

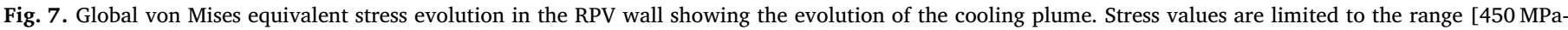
$700 \mathrm{MPa}$ (b) Hoop and axial distribution in the inner RPV surface during the cooling plume. 


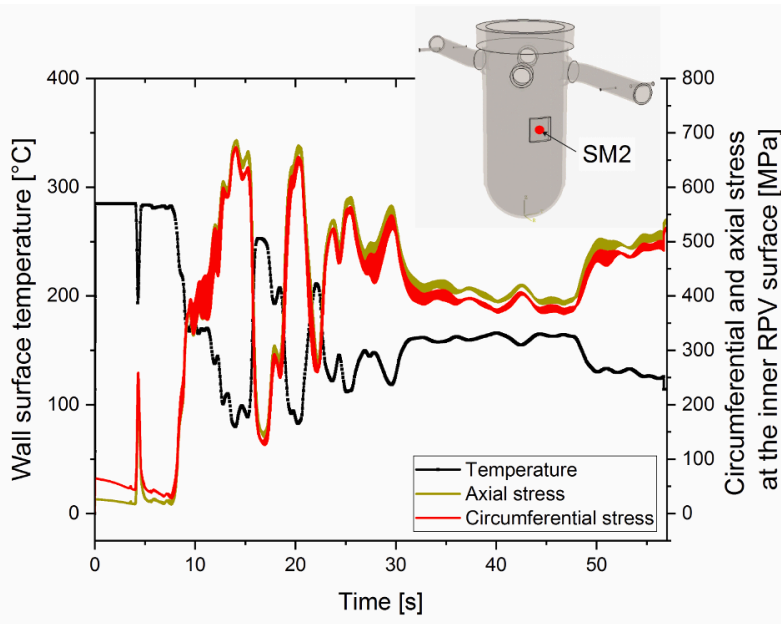

(a)

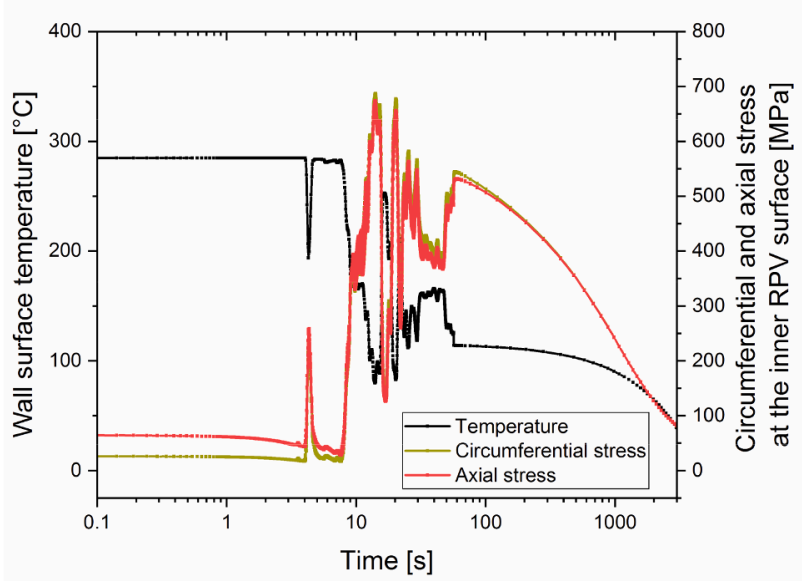

(b)

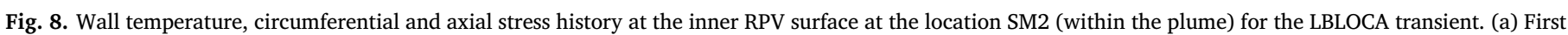
56.7 s. (b) Linear extrapolation until $3000 \mathrm{~s}$.

Fig. 9 shows the axial stress and temperature distributions along the vessel wall thickness for different times during the LBLOCA transient and within the plume region in a path located in the location SM2. The axial stress distribution displays a jump in the cladding/ferritic-steel interface. The highest stress values are in the inner wall surface ( $\mathrm{x}$ / thickness $=0.0$ ). This magnitude of stress in the inner surface is not physical, since in the real case the cladding material plastifies during the PTS. The deepest point of the crack is indicated (crack depth) and it is clear that the crack tip is outside the area of highest stresses. This fact also show that the linear elastic fracture mechanics is a reasonable assumption.

$\overline{\mathbf{u}_{X F E M}(\mathbf{x})=\sum_{\substack{i \in I \\ \text { Clasical }}}^{N_{i}(\mathbf{x}) \mathbf{u}_{i}+\sum_{i \in J} N_{i}(\mathbf{x}) H(\boldsymbol{x}) \mathbf{a}_{i}}+\sum_{\text {Discontinuity }}+\underset{\text { Enriched }}{\sum_{i \in K}[N_{i}(\mathbf{x}) \underbrace{4}_{\alpha=1} F_{\alpha}(\mathbf{x}) \mathbf{b}_{i \alpha}]} \text { Singularity }}$

\section{Stress intensity factor calculation}

\subsection{Basics of extended finite element method}

The extended finite element method (XFEM) extends the classical
FEM by enriching the solution space of the differential equations in order to include discontinuous functions to represent the crack (Duflot, 2007; Sukumar et al., 2000). The XFEM was implemented in ABAQUS and was developed to eases problems in crack propagation on nonstructured, refined meshes, thus, re-meshing is avoided. The XFEM approximation consists of standard elements in the major part of the domain and enriched elements in the sub-domain that capture the crack face discontinuity and the singularity in the near crack tip asymptotic stress field. The method is based on the enrichment of the finite element with additional degrees of freedom (DOF) that are associated with the nodes of the element affected by the crack (Moës et al., 1999). The displacement approximation for XFEM is given by:

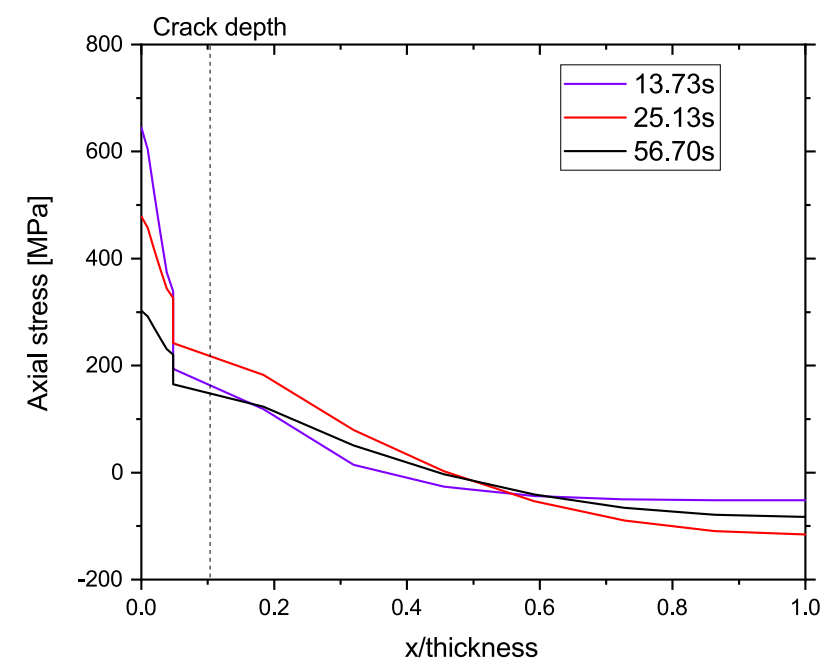

where $I$ is the set of all nodes in the mesh, $N_{i}(\mathbf{x})$ are the nodal shape functions and $\mathbf{u}_{i}$ stand for the physical nodal displacement for non-enriched nodes at node $i$. The sets $J$ and $K$ contain the nodes enriched with the Generalized Heaviside function $H(\mathbf{x})$ and the crack tip functions $F_{\alpha}(\mathbf{x})$, respectively, and with $\mathbf{a}_{i}$ and $\mathbf{b}_{i \alpha}$ the corresponding degrees of freedom.

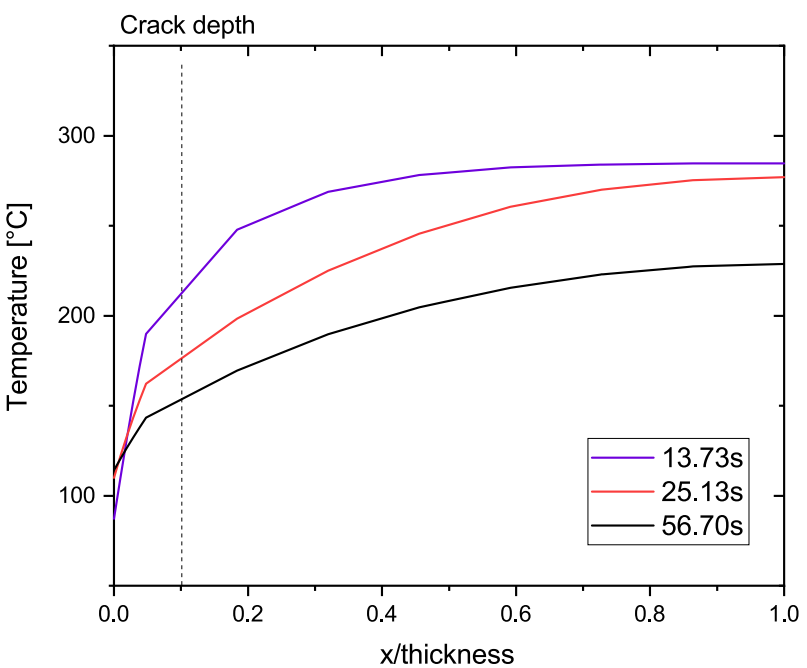

Fig. 9. Axial stress without the crack and (b) temperature distributions along the vessel wall for different time during the LBLOCA transient $(x /$ thickness $=0.0$ indicates the inner surface, $\mathrm{x} /$ thickness $=1.0$ indicates the outer surface of the vessel). It is indicated the deepest location of the crack (crack depth). 


\subsection{SIF extraction: interaction integral method}

In ABAQUS, the interaction integral is used to obtain the stress intensity factor in mixed mode problems. This method was introduced by Shih et al. (Shih and Asaro, 1988) and is based on the $J$-integral. The stress intensity factor for the elastic material can be related to the energy release rate, $\mathcal{G}$, through (Barnett and Asaro, 1972),

$J=\mathcal{G}=\frac{1}{8 \pi} \mathbf{K}^{T} \cdot \mathbf{B}^{-1} \cdot \mathbf{K}$,

with $\mathbf{K}=\left[K_{I}, K_{I I}, K_{I I I}\right]^{T}$ and $K_{I}, K_{I I}, K_{I I I}$ stand for SIF in mode $m=I, I I, I I I$. For homogeneous, isotropic material, $\mathbf{B}=\operatorname{Diag}\left[E^{\prime}, E^{\prime}, 2 G\right]$ and stands for the pre-logarithmic energy factor matrix, where $E^{\prime}=E / 2(1+v)$.

The corresponding SIF $(\mathbf{K})$ are calculated as

$\mathbf{K}=4 \pi \mathbf{B} \cdot \mathbf{J}_{\text {int }}^{\alpha}$,

where the interaction energy integral is (ABAQUS, 2012),

$J_{\text {int }}^{\alpha}=\lim _{\Gamma \rightarrow 0} \int_{\Gamma} \mathbf{n} \cdot \mathbf{M}^{\alpha} \cdot \mathbf{q} d \Gamma$,

where $\Gamma$ stands for a contour that lies in the normal plane at the position $s$ along the crack front, beginning on the bottom surface of the crack and ending on the top surface as shown in the Fig. 10. $\mathbf{n}$ is the outward normal to the area of the small tubular surface enclosing the crack tip $d A=d s d \Gamma$ and $\mathbf{q}$ is the local direction of the virtual crack propagation. The limit indicates that $\Gamma$ shrinks on the crack tip. $\mathbf{M}^{\alpha}$ stands for the Eshelby's momentum tensor in terms of the auxiliary displacement, strain and stress fields and is given by

$\mathbf{M}^{\alpha}=\sigma: \varepsilon_{\text {aux }}^{\alpha}: \mathbf{I}-\sigma \cdot\left(\frac{\partial \mathbf{u}}{\partial \mathbf{x}}\right)_{\text {aux }}^{\alpha}-\sigma_{\text {aux }}^{\alpha} \cdot \frac{\partial \mathbf{u}}{\partial \mathbf{x}}$

The mixed-mode stress intensity factors can be extracted from the Eq. (3) through an appropriate definition of the auxiliary fields. Usually, the auxiliary fields are selected to be Williams series for a straight crack. For curved and nonplanar cracks, different approaches can be considered (González-Albuixech et al., 2013; Gosz and Moran, 2002).

\subsection{Submodeling}

Integrity assessment of RPVs can be performed either by deterministic fracture mechanics (DFM) or by probabilistic fracture mechanics (PFM) analyses. The difference between the two approaches is that the input data (material properties, size, type, orientation, density and locations of the defects) are considered as random in the PFM. Here, we use the deterministic approach (DFM). For the description of a local defect in the DFM, a refined finite element model of the crack geometry has to be defined. Abaqus allows us to define sub-models from a global finite element model of the RPV avoiding expensive calculations with the only refinement in the region of interest (the crack). This technique is referred as submodelling and makes affordable the calculation of the SIF in local region of interest. A submodel is a region of the global model, which is subjected to a node base boundary condition. This uses the nodal results field to interpolate global model results on the submodel nodes (ABAQUS, 2012). Thus, the finite element model can be reduced in size and the domain around the crack can be refined.

\subsection{Fracture mechanics model}

For the integrity assessment of the reference RPV, several submodels are considered in order to evaluate different possible crack locations (Fig. 11(a)). The sub-models are identified as SM1: close to nozzle and outside the core region, SM2: within the plume and where maximum axial and circumferential stresses are expected in the core region and SM3: far from the cooling plume. In every sub-model, a surface crack with depth of $a=17 \mathrm{~mm}$ and aspect ratio of 6 is considered (length/depth $2 c / a=6$ ) as shown in Fig. 11(b). The crack depth/vessel wall thickness ratio is $1 / 10$ and corresponds to 2 times the non-destructive detection limit. Cracks can be oriented axial or circumferential as in Fig. 11(c) and (d), respectively. The analysis is based on the comparison of $K_{I}$ with $K_{I C}$, where the material fracture toughness $K_{I C}$ is calculated according to the American Society of Mechanical Engineers method (ASME-code, 1995) and corresponds to $K_{I C}=36.5+22.78 \exp \left[0.036\left(T-R T_{N D T}\right)\right]$. The neutron irradiation effect is considered in the $R T_{N D T}$, which in this analysis is set to $93^{\circ} \mathrm{C}$.

In Fig. 12, $K_{I}$-temperature curves are depicted for the MBLOCA calculated in (González-Albuixech et al., 2016) and LBLOCA transients calculated for the axial and circumferential cracks using the discussed approach. The result compares the stress intensity factor obtained for the SM2 submodel within the plume and in a location subjected to intense irradiation. In the MBLOCA, the SIF increases with transient time, reaching a maximum of $98.42 \mathrm{MPa} \cdot \mathrm{m}^{0.5}$. Oscillations are not seen in the MBLOCA response. According to this result the margin between the SIF for MBLOCA and the fracture toughness is small. For the LBLOCA the SIF presents several fluctuations due to the oscillation of the plume around the location of the crack and reaches a maximum of $85 \mathrm{MPa} \cdot \mathrm{m}^{0.5}$. In contrast to MBLOCA, in this case the margin is large. Unlike in the MBLOCA, note that the cladding was not neglected in case of LBLOCA for the thermal and stresses calculation, which causes significant reduction of the stress values at the deepest point of the crack, which is located in the ferritic steel (see Fig. 9(a)) affecting the stress intensity factor in this location. Also, note that considering the plastic behavior of the material would lead to lower SIF in case of a through-clad defect as was shown in (Qian and Niffenegger, 2013).

The MBLOCA transient was performed during about $793 \mathrm{~s}$ and the SIF decreases enough to consider the transient to be finalized. Unlike the MBLOCA, the SIF in the LBLOCA reaches $71.8 \mathrm{MPa} \cdot \mathrm{m}^{0.5}$ values of SIF for $56 \mathrm{~s}$ and after $3000 \mathrm{~s}$ the transient is finalized. In order to understand these significant differences in the SIF, the temperature evolution is displayed in the Fig. 13 on the inner wall surface and the crack tip in both MBLOCA and LBLOCA during the first $200 \mathrm{~s}$. Several important features are remarkable, firstly, the MBLOCA temperature drops slower than LBLOCA temperature, secondly, the meandering of the plume is more noticeable in case of LBLOCA causing more oscillations in temperature, probably because of the mixing process and evaporation in this transient and finally, the temperature gradient is steeper for the MBLOCA after $60 \mathrm{~s}$. Nevertheless, a slower temperature drop in the MBLOCA does not explain the low value of the SIF, since a slower temperature drop leads to a lower stress gradient. On the other hand, the effect of oscillation in temperature are limited to the surface and the variations disappear close to the crack tip. More important in the SIF value is the effect to the temperature gradient at the crack tip. According to Fig. 13, the temperature under the condition MBLOCA is larger than LBLOCA for the initial stage. After $80 \mathrm{~s}$ the temperature for

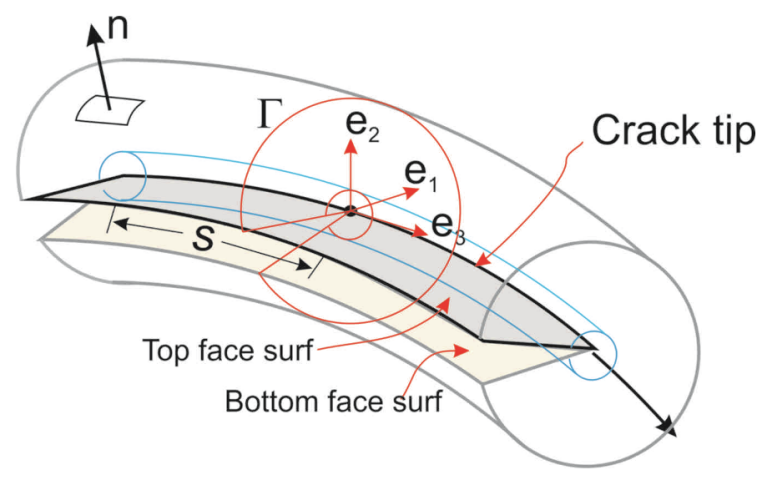

Fig. 10. Surface area enclosing the domain of volume that includes the crack front region. 
(a) Submodels definition

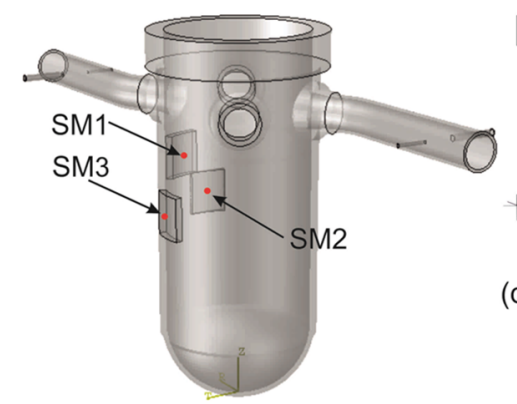

(b) Crack geometry

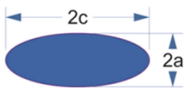

(c) Axial crack

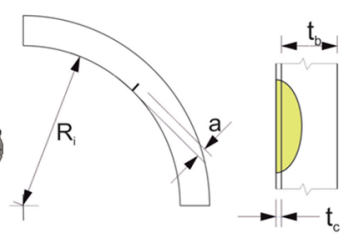

(d) Circumferential crack

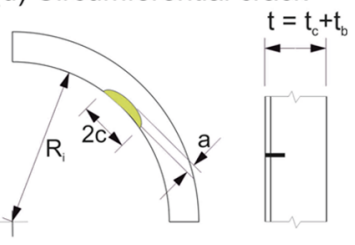

Fig. 11. Definition of the submodels SM1 close to nozzle, SM2 within plume and SM3 far from plume, (b) Crack geometry with dimenstions (c) axial surface crack geometry scheme (d) circumferential surface crack.

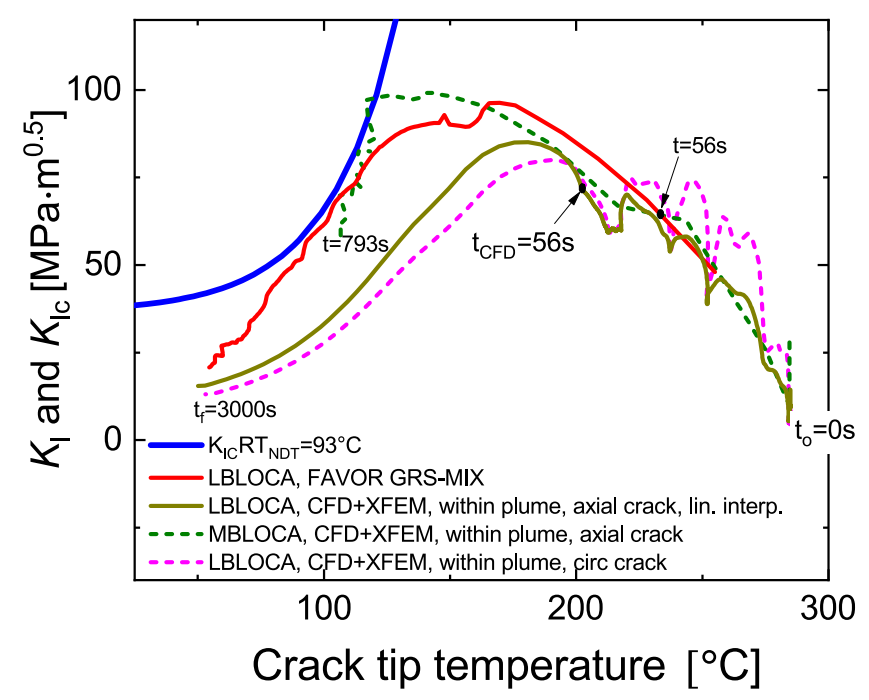

Fig. 12. Comparison of the stress intensity factor during non-uniform cooling, LBLOCA and MBLOCA transient, within the plume in the deepest location of the axial crack versus the crack tip temperature for CFD + XFEM for location SM2.

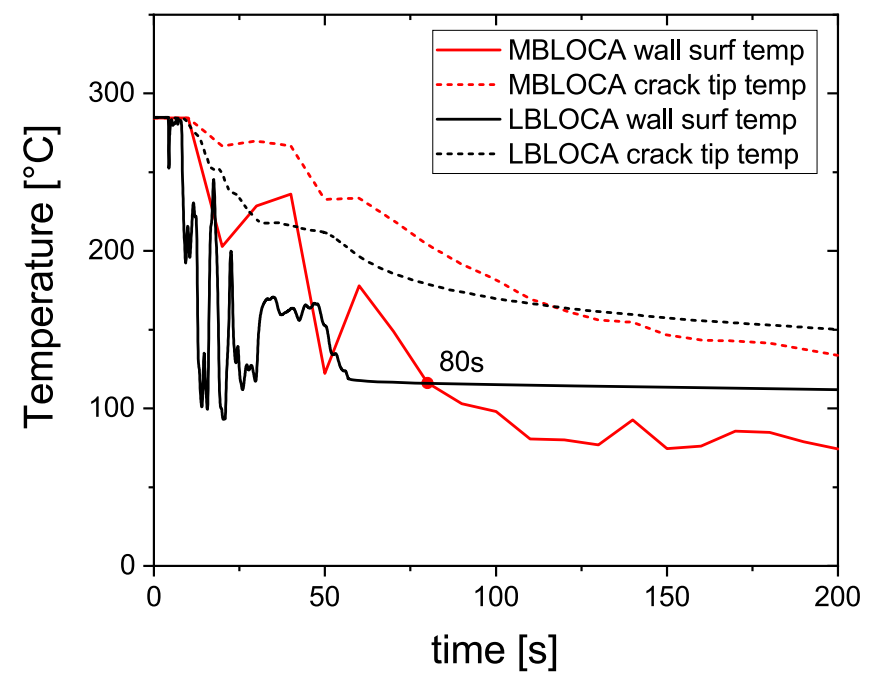

Fig. 13. Temperature evolution for MBLOCA and LBLOCA transients at inner wall surface and crack tip in the deepest location for SM2.
MBLOCA becomes lower than under LBLOCA during the remaining transient. This is a clear consequence of the linear extrapolation assumed for the LBLOCA condition. A steeper gradient in MBLOCA is consistent with a higher SIF. From this, it seems that a linear extrapolation of the temperature produces non-conservative results for LBLOCA.

Additionally the stress intensity factors for circumferential and axial cracks are also shown in Fig. 12 for the location SM2. According to these results, there are not significant differences regarding the orientation of the crack as the stress state in Fig. 7 shows similar magnitude in the axial and circumferential directions.

Fig. 12 also includes the solution for SIF calculated with FAVOR. It is important to keep in mind that FAVOR is a system code that disregards the details of the PTS. From this result, the following comments can be drawn. On one hand, FAVOR is used in combination with GRSMIX, the later allows us to perform the thermo-hydraulic analysis in order to obtain the thermal loads considering the cooling plume. GRXMIX is a one dimensional code, developed from UPTF-TRAM experiments for pressurized water reactors, which can be described as a set of correlations and equations deduced from the experiments and yields good results for NPPs with similar geometric conditions as these of the experiments. Therefore, the result for FAVOR + GRS-MIX might introduce simplifications related to the thermal boundary conditions that are considered explicitly in the CFD calculation. On the other hand, CFD might introduce uncertainties due to the simplifications and assumptions in models implemented. It is expected that GRS-MIX is incapable to predict oscillations of the temperatures and consequently of the SIFs due to the meandering of the plume. The resulting curve shows a rather smooth shape. On the other hand, computational fluid dynamics, instead, consider the details of the mixing flow and in consequence, oscillations in temperature on the surface wall and crack tip reflect the effect of the meandering of the plume. From the above, the authors believe that the differences between FAVOR + GRS-MIX and CFD + XFEM are because of the manner of the calculation is performed in each approach.

For locations SM1 and SM3, the stress intensity factors are depicted in Fig. 14. The SIF for a circumferential crack in a location close to the nozzle (SM1) reaches a value of about $100 \mathrm{MPa} \cdot \mathrm{m}^{0.5}$ which is higher than the obtained in the location SM2. However, as the point SM1 is located out the core region, where the irradiation effect is less severe and the material is less embrittled, does not represent a critical case for the integrity of the RPV. The maximum value for the circumferential crack is $7 \%$ lower representing an even less severe condition. In a location in the core region and out of the cooling plume (SM3) the SIF shows similar magnitude in circumferential and axial location with a maximum value around $96.5 \mathrm{MPa} \cdot \mathrm{m}^{0.5}$.

\section{Theoretical result}

One way to verify whether the presented model correctly computes the stress intensity factor is to compare these results with an analytical solution that represents a similar case as possible. In Anderson (Anderson, 1995), the analytical solution for superficial crack in a cylinder subjected to uniform tension was presented, which is given by,

$K_{I}^{t h}=\sigma_{t} \sqrt{\frac{\pi a}{Q}} F_{t}$

with the following weight function,

$F_{t}=1+\left[0.02+\xi(0.0103+0.00617 \xi)+0.0035(1+0.7 \xi)\left(\frac{R}{t}-5\right)^{0.7}\right] Q^{2}$

with $\xi=2 c / t$ and $Q=1+1.464(a / c)^{1.65}$.

Unlike the solution presented by Anderson, the stresses in RPV wall are not uniform along the wall vessel direction as was shown in Fig. 9(a). Therefore, to make a more reasonable comparison, the average tension was considered instead. The results in Fig. 15(a) show 

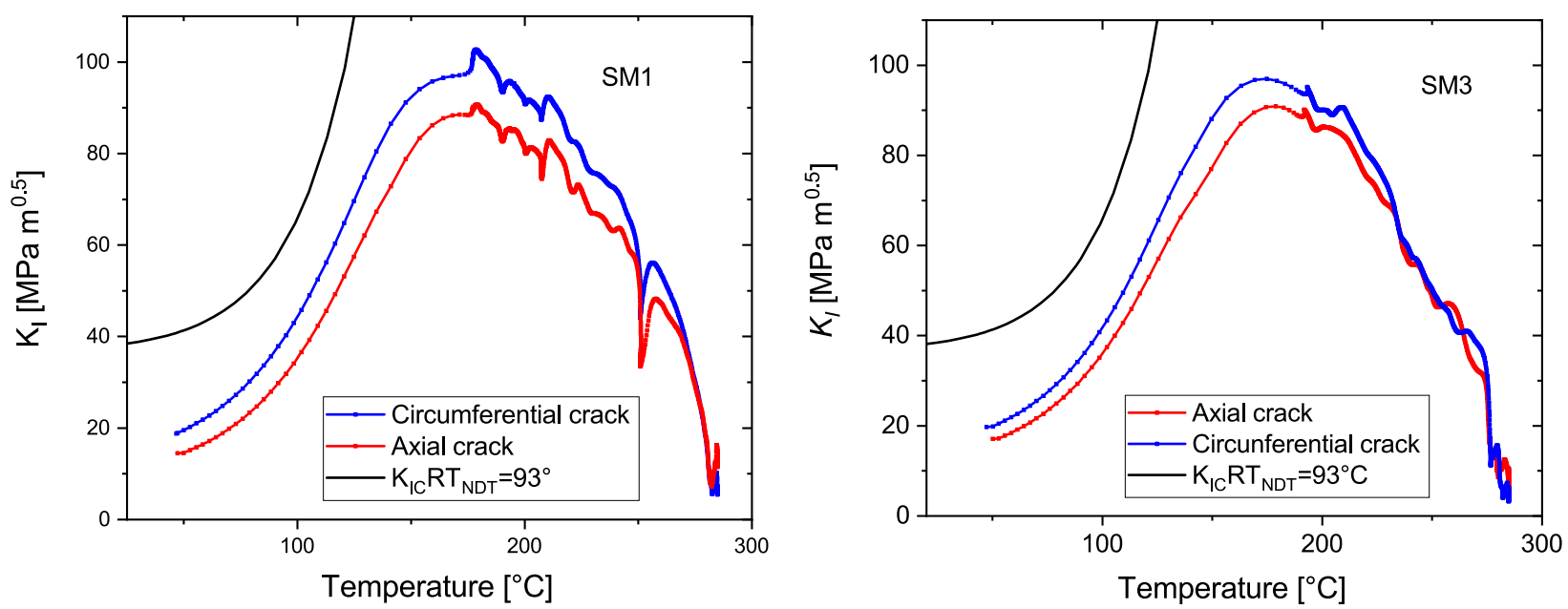

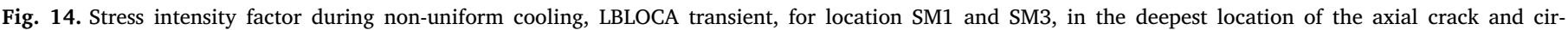
cumferential versus the crack tip temperature for CFD + XFEM.

good agreement between the theoretical solution and the finite element estimation. Fig. 15(b) displays the error between the theoretical solution and the XFEM result. According to this result, the differences reach maximum values around $18 \mathrm{MPa} \cdot \mathrm{m}^{0.5}$ at the beginning of the transient and reduces significantly with time.

\section{Conclusions}

A comprehensive multi-step simulation scheme was introduced to simulate a large break LOCA scenario with a postulated guillotine break in one of the hot legs for the structural integrity analysis of a reactor pressure vessel. Each step of the simulation scheme considers details of the underlying physics and geometry of the reactor. It was demonstrated that the principle of the combined one-way coupled system code, CFD and structural mechanics codes can be used for the fracture analysis in case of a transient accident, which involves two-phase steam-water flow.

In the thermo-hydraulic analysis, we considered the two-phase steam-water flow in the PWR reactor, which was studied using state of the art techniques with ANSYS fluent code. The CFD calculation to obtain the temperature of the fluid considers the safety injection pumps and accumulators as well as the realistic initial and boundary conditions. Although some assumptions are required to make the CFD calculation feasible, the results show that the mixing phenomena due to the presence of the two-phase flow are fairly represented. However, the model presented here to represent the considered two-phase PTS situation is a proof of the principle and needs further development and validation before it can be judged to be sufficiently mature for industrial application. In addition, the complex fluid-structure interaction is well represented and the complex fluid dynamics around the neutron shield is captured showing detachment of the cold water along the downcomer and splitting of the flow during the beginning of the transient. The main result of this step of the analysis is the temperature distribution and especially in the cooling plume as it is the input of the stress analysis. The cooling plume shows a meandering instead of having a steady behavior.

The stress analysis accounts for the material dependence on temperature and dissimilar materials. On one hand, the stress contours in the inner surface shows that the stress distribution follows the distribution given by the temperature. It is clear from the results that the meandering of the cooling plume directly affects the stresses at the RPV wall and subsequently produces oscillations in the temperature and stress evolution in any point within its influence. The cooling plume size evolves as the vessel is filled with cold water in a way that at the end of the calculated transient almost disappeared giving rise to a rather uniform distribution of the stress. On the other hand, the
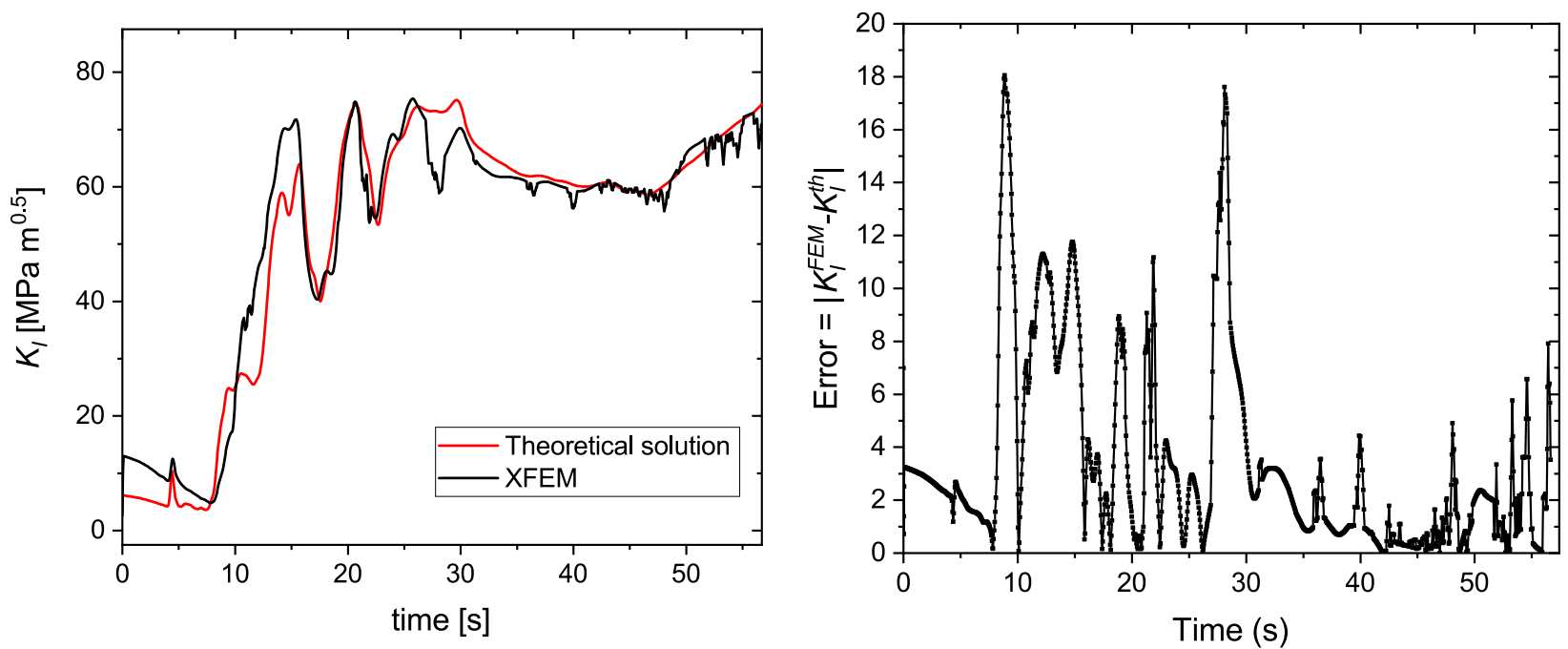

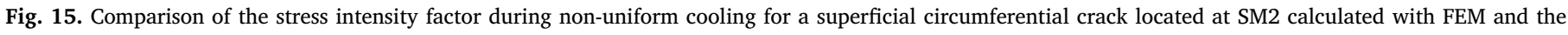
theoretical solution subjected to uniform tensile stress. (b) Error between the theoretical and the XFEM solution. 
distribution of the stress along the thickness of the RPV wall drops at the material interface and consequently the stress magnitude at the crack tip distance reduces significantly when the cladding is taken into account.

The structural integrity analysis is completed with fracture mechanics calculation. The sub-modelling allows us to save time in performing this analysis and to locate cracks in different orientations more systematically. In consequence, circumferential and axial crack can be put inside and outside the cooling plume, the core region and close to the nozzle to see the effect of the transient under different stress states. Based on the fracture analysis, the following conclusions can be drawn:

- The comparison of the stress intensity factor calculated based on FAVOR + GRS-MIX and CFD + XFEM shows large differences because of the basic assumptions in each method, i.e. one dimensional analysis assuming steady cooling plume in GRS-MIX while nonuniform oscillating cooling effect, three dimensional analysis in CFD + XFEM. Additionally, GRS-MIX is based on engineering correlation developed from UPTF-TRAM experiments and the accuracy of the predictions depends on how similar are the conditions of the experiments and the studied case.

- Comparison of the MBLOCA and LBLOCA transient shows significant differences. It is important to keep in mind that MBLOCA transient was analyzed disregarding the cladding and considering a single material. As seen in the results, the stress values drop at the material interface when cladding is considered in the analysis, such as the stress state at the deepest point of the crack tip is significantly lower than in the internal surface. Another difference is that for LBLOCA, there is a significant loss of cooling capacity because the phase changes and at low pressure, the injected water evaporates rapidly filling up the vessel with vapor. According to the results, which are partially based on a linear extrapolation of the RPV wall temperature, the LBLOCA is less severe than MBLOCA and has a larger safety margin.

- The theoretical solution for a cylinder subjected to uniform tension (averaged axial stress from FEM) with internal superficial semielliptical crack compares well with finite element calculation.

\section{Acknowledgement}

The authors are grateful for the financial support of the PROBAB project provided by the Swiss Federal Nuclear Safety Inspectorate (ENSI) (Contract No. H-101247).

\section{References}

ABAQUS, 2012. Theory Manual and User's Manual. Dassault System Simulia Corp, Providence, RI, USA.

Anderson, T.L., 1995. Fracture Mechanics, Fundamentals and Aplications. CRC Press LLC, Boca Raton, Florida.

ANSYS, 2013. FLUENT 15.0. Theory guide.

Apanasevich, P., Coste, P., Ničeno, B., Heib, C., Lucas, D., 2014. Comparison of CFD simulations on two-phase Pressurized Thermal Shock scenarios. Nucl. Eng. Des. 266, $112-128$.

ASME-code, 1995. ASME boiler and pressure vessel code, section III, nuclear power plants components.

Barnett, D.M., Asaro, R.J., 1972. The fracture mechanics of slit-like cracks in anisotropic elastic media. J. Mech. Phys. Solids 20, 353-366.

Bass, B.R., Pugh, C.E., Sievers, J., Schulz, H., 2001. Overview of the International Comparative Assessment Study of Pressurized Thermal-Shock in Reactor Pressure Vessels (RPV PTS ICAS). Int. J. Press. Vessels Pip. 78, 197-211.

Boros, I., Aszódi, A., 2008. Analysis of thermal stratification in the primary circuit of a VVER-440 reactor with the CFX code. Nucl. Eng. Des. 238, 453-459.

Chauliac, C., Aragonés, J.-M., Bestion, D., Cacuci, D.G., Crouzet, N., Weiss, F.-P. Zimmermann, M.A., 2011. NURESIM - a European simulation platform for nuclear reactor safety: multi-scale and multi-physics calculations, sensitivity and uncertainty analysis. Nucl. Eng. Des. 241, 3416-3426.
Coste, P., 2013. A large interface model for two-phase CFD. Nucl. Eng. Des. 255, 38-50. Duflot, M., 2007. A study of the representation of cracks with level sets. Int. J. Numer. Meth. Eng. 70, 1261-1302.

Fillery, B.P., Hu, X.Z., 2012. Compliance based assessment of stress intensity factor in cracked hollow cylinders with finite boundary restraint: application to thermal shock part II. Eng. Fract. Mech. 79, 18-35.

González-Albuixech, V.F., Giner, E., Tarancón, J.E., Fuenmayor, F.J., Gravouil, A., 2013. Domain integral formulation for 3-D curved and non-planar cracks with the extended finite element method. Comput. Methods Appl. Mech. Eng. 264, 129-144.

González-Albuixech, V.F., Qian, G., Sharabi, M., Niffenegger, M., Niceno, B., Lafferty, N., 2015. Comparison of PTS analyses of RPVs based on 3D-CFD and RELAP5. Nucl. Eng. Des. 291, 168-178.

González-Albuixech, V.F., Qian, G., Sharabi, M., Niffenegger, M., Niceno, B., Lafferty, N., 2016. Integrity analysis of a reactor pressure vessel subjected to a realistic pressurized thermal shock considering the cooling plume and constraint effects. Eng. Fract. Mech. 162, 201-217.

Gosz, M., Moran, B., 2002. An interaction energy integral method for computation of mixed-mode stress intensity factors along non-planar crack fronts in three dimensions. Eng. Fract. Mech. 69, 299-319.

Gravouil, A., Moës, N., Belytschko, T., 2002. Non-planar 3D crack growth by the extended finite element and level sets-Part II: level set update. Int. J. Numer. Meth. Eng. 53, 2569-2586.

Jaros, M., 2017. Computational Fluid Dynamics Study of Pressurized Thermal Shock Transients in the Reactor Pressure Vessel. Nuclear Energy and Safety (NES) Laboratory for Thermal-Hydraulics. Paul Scherrer Institut (PSI), Villigen PSI, Switzerland.

Lee, W.H., 1980. A Pressure Iteration Scheme for Two-Phase Modeling. Los Alamos Scientific Laboratory, pp. 407-431.

Lucas, D., Bestion, D., Bodèle, E., Scheuerer, M., D'Auria, F., Mazzini, D., Smith, B., Tiselj, I., Martin, A., Lakehal, D., Seynhaeve, J.-M., Kyrki-Rajamäki, R., Ilvonen, M., Jiri, M., 2007. On the simulation of two-phase flow pressurized thermal shock (PTS). Proceedings - 12th International Topical Meeting on Nuclear Reactor Thermal Hydraulics, NURETH-12.

Lucas, D., Bestion, D., Bodèle, E., Coste, P., Scheuerer, M., D'Auria, F., Mazzini, D., Smith, B., Tiselj, I., Martin, A., Lakehal, D., Seynhaeve, J.-M., Kyrki-Rajamäki, R., Ilvonen, M., Macek, J., 2009. An overview of the pressurized thermal shock issue in the context of the NURESIM project. Sci. Technol. Nucl. Instal. 2009, 13.

Ma, C.C., Huang, J.I., Tsai, C.H., 1994. Weight functions and stress intensity factors for axial cracks in hollow cylinders. J. Pressure Vessel Technol. 116, 423-430.

Mahaffy, J., Chung, B., Song, C., Dubois, F., Graffard, E., Ducros, F., Heitsch, M., Scheuerer, M., Henriksson, M., Komen, E., Moretti, F., Morii, T., Muehlbauer, P., Rohde, U., Smith, B.L., Watanabe, T., Zigh, G., 2007. Best Practice Guidelines for the use of CFD in Nuclear Reactor Safety Applications. Nuclear Energy Agency of the OECD (NEA), pp. 166.

Moës, N., Dolbow, J., Belytschko, T., 1999. A finite element method for crack growth without remeshing. Int. J. Numer. Meth. Eng. 46, 131-150.

Murray, C., 2007. Overview of TRACE v5.0. Regulatory Information Conference Slides. U.S.N.R.C.

Odette, G., Lucas, G., 1986. Irradiation Embrittlement of Reactor Pressure Vessel Steels: Mechanisms, Models, and Data Correlations, Irradiation Embrittlement of Reactor Pressure Vessel Steels: Mechanisms, Models, and Data Correlations.

Oliveira, R., Wu, X.R., 1987. Stress intensity factors for axial cracks in hollow cylinders subjected to thermal shock. Eng. Fract. Mech. 27, 185-197.

Qian, G., Niffenegger, M., Sharabi, M., Lafferty, N., 2016. Deterministic and Probabilistic PTS Study for a Reactor Pressure Vessel Considering Plume Cooling Effects. PVP: Vol. 6A-2016. Presented at the ASME 2016 Pressure Vessels and Piping Conference, PVP 2016. V06AT06A040.

Qian, G., Niffenegger, M., 2013. Integrity analysis of a reactor pressure vessel subjected to pressurized thermal shocks by considering constraint effect. Eng. Fract. Mech. 112-113, 14-25.

RELAP5-3D, 1999. RELAP5/Mod3 Code Manual, Vol: Code Structure, System Models and Solution Methods. The Thermal Hydraulics Group, Idaho.

Sharabi, M., González-Albuixech, V.F., Lafferty, N., Niceno, B., Niffenegger, M., 2016. Computational fluid dynamics study of pressurized thermal shock phenomena in the reactor pressure vessel. Nucl. Eng. Des. 299, 136-145.

Shih, C.F., Asaro, R.J., 1988. Elastic-plastic analysis of cracks on bimaterial interfaces: part I-small scale yielding. J. Appl. Mech. 55, 299-316.

Sukumar, N., Moës, N., Moran, B., Belytschko, T., 2000. Extended finite element method for three-dimensional crack modelling. Int. J. Numer. Meth. Eng. 48, 1549-1570.

Toppila, T., 2008. CFD simulation of Fortum PTS experiment. Nucl. Eng. Des. 238, 514-521.

Wang, M., Bai, L., Wang, L., Qiu, S., Tian, W., Su, G.H., 2017a. Thermal hydraulic and stress coupling analysis for AP1000 Pressurized Thermal Shock (PTS) study under SBLOCA scenario. Appl. Therm. Eng. 122, 158-170.

Wang, M., Zuo, Q., Yu, H., Tian, W., Su, G.H., Qiu, S., 2017b. Multiscale thermal hydraulic study under the inadvertent safety injection system operation scenario of typical pressurized water reactor. Sci. Technol. Nucl. Instal. 2017, 15.

Williams, P.T., Dickson, T.L., Yin, S., 2004. Fracture Analysis of Vessels - OakRidge FAVOR, Computer Code: Theory and Implementation of Algorithms, Methods and Correlations. NUREG/CR-6854, 04.1. NUREG. 